Article

\title{
Efficient Production of Multi-Layer Graphene from Graphite Flakes in Water by Lipase-Graphene Sheets Conjugation
}

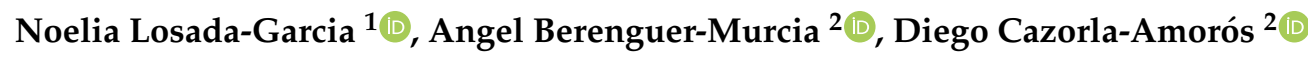 \\ and Jose M. Palomo ${ }^{1, *(1)}$ \\ 1 Department of Biocatalysis. Institute of Catalysis (CSIC). Marie Curie 2. Cantoblanco. Campus UAM, \\ 28049 Madrid, Spain; n.losada@csic.es \\ 2 Instituto Universitario de Materiales y Departamento de Química Inorgánica, Universidad de Alicante, \\ Apartado 99, San Vicente del Raspeig, E-03080 Alicante, Spain; a.berenguer@ua.es (A.B.-M.); \\ cazorla@ua.es (D.C.-A.) \\ * Correspondence: josempalomo@icp.csic.es; Tel.: +34-9158-5476-8
}

Received: 5 September 2019; Accepted: 18 September 2019; Published: 19 September 2019

\begin{abstract}
Biographene was successfully produced in water from graphite flakes by a simple, rapid, and efficient methodology based on a bioexfoliation technology. The methodology consisted in the application of a lipase, with a unique mechanism of interaction with hydrophobic surfaces, combined with a previous mechanical sonication, to selectively generate lipase-graphene sheets conjugates in water at room temperature. The adsorption of the lipase on the graphene sheets permits to keep the sheets separated in comparison with other methods. It was possible to obtain more than $80 \%$ of graphene (in the form of multi-layer graphene) from low-cost graphite and with less damage compared to commercial graphene oxide (GO) or reduced GO. Experimental analysis demonstrated the formation of multi-layer graphene (MLG) mainly using lipase from Thermomyces Lanuginosus (TLL).
\end{abstract}

Keywords: graphene; exfoliation; lipase; graphite; biographene

\section{Introduction}

Graphene is a material with excellent electrical and thermal properties, very high mechanical strength and elasticity which make it ideal for application in areas such as electronics, materials, biomedicine, biotechnology, etc. [1-13].

Production of graphene has been performed by scotch tape peeling [14], different chemical and thermal strategies [15-18], and solvent/surfactant-assisted exfoliation of graphite with sonication [19,20].

In particular, the synthesis of graphene by the chemical reduction of graphene oxide (GO) by the Hummers method represents at present the most scalable method for the production of few-layer graphene $[15,17]$. However, this technique requires very harsh and toxic conditions, which probably causes defects within the graphene sheets, compromising properties and morphology [20].

In this way, in recent years, strategies to synthesize graphene by a more sustainable way have been reported. The direct exfoliation of graphite to graphene in water seems to have the best reported outcome [21-28]. By this route, a few methodologies have been described to produce biographene using different small molecules (aromatic compounds, carbohydrates) [21-23], nanofibers [24], surfactants [25], or plant extracts [26].

In particular, the application of proteins for the exfoliation of graphite is an interesting alternative. The application of a mechanical step to create enough space between graphene layers in graphite (interlayer distance $0.33 \mathrm{~nm}$ ) is needed for the intercalation of proteins (protein size 5-10 nm). A few 
examples have proven to be successful in the application of proteins [27-29]. However, in these cases, proteins come from animal sera or are not sufficiently pure. This is a disadvantage in order to obtain a fully selectively covered surface. Heterogeneous samples are usually obtained using these protein mixtures, where a homogeneous surface coverage should be mandatory. Another important issue is the high-efficiency exfoliation of graphite into single- or few-layered nanoplates, which remains significant and becomes the bottleneck in fundamental studies and applications of graphene.

At present, the most specific methodology is represented by using hydrophobins, which present a hydrophobic part and another hydrophilic [30]. It is demonstrated that they can interact by the hydrophobic area on graphene. Nevertheless, these proteins are very difficult to manipulate, biochemical production is complex producing very low yields and it has been shown that mixtures of graphene and graphite are obtained following this strategy [28].

Therefore, the development of a highly selective methodology to produce a completely homogeneous modification of the graphene protein surface is mandatory. Moreover, from an economical point of view, the availability of the enzyme is critical.

This way, the use of lipases can solve these drawbacks. Lipases are enzymes with a particular structure based on their natural function, fat hydrolysis. In nature, they work at the interface between oil and water [31]. They present an oligopeptide lid with an internal hydrophobic face and external hydrophilic one which is mainly in a closed conformation in homogeneous aqueous media in a certain equilibrium with a very minority open form (Figure 1). However, in the presence of hydrophobic surfaces (solid support, proteins, lipids, etc.) this equilibrium is rapidly shifted to the open conformation where the hydrophobic phase of the lid is exposed to the solvent, generating a big and exclusive hydrophobic pocket which permits to fix the enzyme in this conformation to the hydrophobic surface as an exclusive mechanism. This allows to obtain all the lipase molecules perfectly adsorbed in open conformation (Figure 1) [32-35].

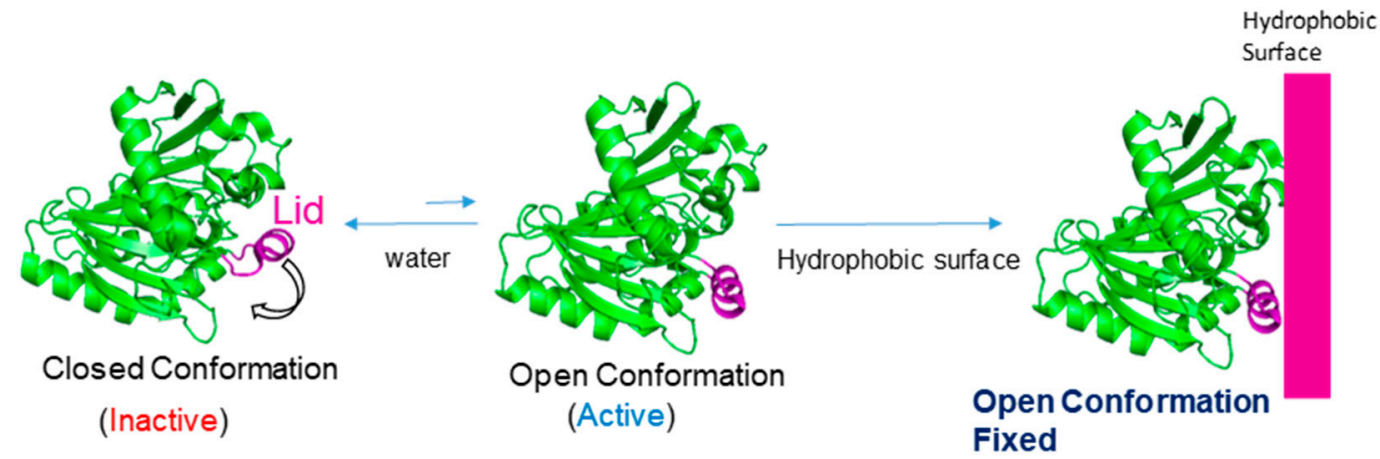

Figure 1. Mechanism and interaction of lipases with hydrophobic surfaces.

This capacity has been demonstrated to work in the presence of different hydrophobic interfaces (detergents, solid materials, hydrophobic proteins) [32-35] (Figure 2).

Recently a lipase interacting with graphene has been described although in all cases as a covalent immobilization technique on graphene oxide using crosslinkers [36,37].

In this work, we applied for the first time the special selective capacity of these lipases for their selective adsorption on graphene from graphite flakes. These represent a very fast, cost-efficient and sustainable methodology for the bioexfoliation of graphite to graphene. These enzymes can be homogeneously located on the graphene surface, permitting their direct production from the graphite present in a water suspension at room temperature. 
A

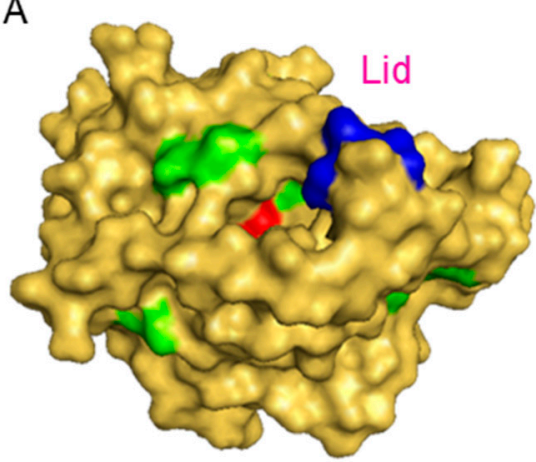

B

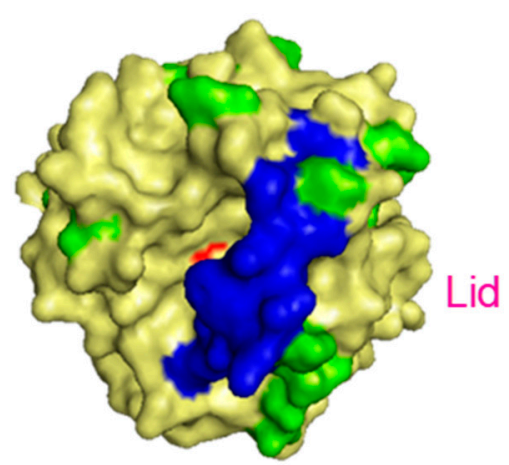

Figure 2. Hydrophobic area and Lid of (A) CAL-B, (B) TLL. Lid (blue) and Hydrophobic area (green).

This also represents a method for the specific functionalization of graphene, because we can selectively control the enzyme location, thus controlling the number of groups (amino, carboxyl) for the modification of graphene.

Furthermore, we demonstrate how the capacity of the lid has an influence on the final results and how it is possible to obtain biographene very easily on a large scale.

\section{Materials and Methods}

\subsection{Materials}

Graphite flakes and p-nitrophenilpropionate (pNPP) were purchased from Sigma-Aldrich Co (St Louis, MO, USA). Lipase B from Candida antarctica (CAL-B) solution and lipase from Thermomyces Lanuginosus (TLL) were obtained from Novozymes (Copenhagen, Denmark). Aqueous solutions were prepared using UltraPure ${ }^{\mathrm{TM}}$ DNase/RNase-Free Distilled Water (Thermo Fisher Scientific). To recover the biohybrids, a Biocen 22 R (Orto-Alresa, Ajalvir, Spain) refrigerated centrifuge was used.

\subsection{Characterization Techniques}

Inductively coupled plasma-optical emission spectrometry (ICP-OES) was performed in an OPTIMA 2100 DV instrument (PerkinElmer, Waltham, MA, USA). X-Ray diffraction (XRD) patterns were obtained using a Texture Analysis D8 Advance Diffractometer (Bruker, Billerica, MA, USA) with $\mathrm{Cu} \mathrm{K} \alpha$ radiation. Transmission electron microscopy (TEM) and high-resolution TEM microscopy (HRTEM) images were obtained on a 2100F microscope (JEOL, Tokyo, Japan). Interplanar spacing in the nanostructures was calculated by using the inversed Fourier transform with the GATAN digital micrograph program (Corporate Headquarters, Pleasanton, CA, USA). Scanning electron microscopy (SEM) imaging was performed on a TM-1000 microscope (Hitachi, Tokyo, Japan). Vibra-Cell ${ }^{\mathrm{TM}}$ Ultrasonic Liquid Processors VCX130 (Sonics) was used for graphite sonication process. Raman spectra were collected at room temperature using a dispersive JASCO NRS-5100 equipment with a focal distance of $300 \mathrm{~mm}$ and a maximum resolution of $1 \mathrm{~cm}-1$. The laser used in the experiments was a solid-state laser $(532 \mathrm{~nm}$ ) with a sample output power of $4 \mathrm{~mW}$. The equipment is coupled to an MPLFLN $20 \times$ UV objective. Prior to analysis, the Raman shift was calibrated using the $520 \mathrm{~cm}^{-1}$ band of a pure silicon sample. Two 60-second scans were performed for each spectrum. The obtained spectra were baseline corrected in order to remove any background fluorescence. Spectrophotometric analyses were run on a V-730 spectrophotometer (JASCO, Tokyo, Japan). Atomic force microscopy images were obtained using an NTEGRA PRIMA NT-MDT microscope. The obtained images were analyzed using the built-in software provided by the manufacturer. 


\subsection{Ultrasonication of Graphite Flakes}

\subsubsection{Method 1: Simple Sonication of Graphite Flakes}

The graphite flakes $(1 \mathrm{~g})$ are added together with $20 \mathrm{~mL}$ of distilled water to a $50 \mathrm{~mL}$ centrifuge tube (50 mL Falcon tube). Then, the graphite is exfoliated by alternating cycles of $5 \mathrm{~min}$ sonication/rest, for $30 \mathrm{~min}$ at an amplitude of $80 \%$. To avoid excessive heating of the mixture, the $50 \mathrm{~mL}$ Falcon tube is introduced into a mixture of ice and cold acetone. This exfoliation allows the weakening of the bonds between sheets. The non-exfoliated graphite is separated from the mixture by centrifugation. The mixture was transferred to $15 \mathrm{~mL}$ centrifuge tubes (15 mL Falcon tubes) and centrifuged at $400 \mathrm{rpm}$ for $1 \mathrm{~min}$. The supernatant is carefully separated from the unfolded graphite solid. Finally, the supernatant was placed in a Petri dish and dried in the stove at $50{ }^{\circ} \mathrm{C}$. The method allows obtaining $100 \mathrm{mg}$ of Sgraphene-1, final yield of $10 \%$.

\subsubsection{Method 2: Double Sonication of Graphite Flakes}

The graphite flakes $(1 \mathrm{~g})$ are added together with $20 \mathrm{~mL}$ of distilled water to a $50 \mathrm{~mL}$ centrifuge tube (50 $\mathrm{mL}$ Falcon tube). Once this is done, the graphite is exfoliated by alternating cycles of $5 \mathrm{~min}$ sonication/rest, for $1 \mathrm{~h}$ at an amplitude of $80 \%$. To avoid excessive heating of the mixture, the $50 \mathrm{~mL}$ Falcon tube is introduced into a mixture of ice and cold acetone. This exfoliation allows the weakening of the bonds between sheets. The non-exfoliated graphite is separated from the mixture by centrifugation. The mixture was transferred to $15 \mathrm{~mL}$ centrifuge tubes ( $15 \mathrm{~mL}$ Falcon tubes) and centrifuged at $400 \mathrm{rpm}$ for $1 \mathrm{~min}$. The black supernatant was carefully separated from the graphite solid. Finally, it was placed in a Petri dish and dried in the stove at $50{ }^{\circ} \mathrm{C}$. The method allows obtaining $300 \mathrm{mg}$ of Sgraphene-2, final yield of $30 \%$.

\subsection{Exfoliation of Graphite Flakes Using Lipase}

\subsubsection{Method 3: Double Sonication of Graphite Flakes + Selective Lipase Adsorption}

The graphite flakes $(1 \mathrm{~g})$ in $20 \mathrm{~mL}$ of water were sonicated as described in Method 2. After that, commercial lipase solution of TLL $(0.43 \mathrm{~mL})$ or commercial lipase solution of CAL-B $(1 \mathrm{~mL})$, in both cases offering $5 \mathrm{mg}$ lipase, were directly added to that and allowed to stir for a period of time between $30 \mathrm{~min}$ and $1 \mathrm{~h}$. The selective adsorption of the lipase was followed by measuring the supernatant using the pNPP activity assay (described below). After lipase immobilization, the suspension turned cloudy black. Then, the mixture was transferred to $15 \mathrm{~mL}$ Falcon centrifuge tubes and centrifuged at $400 \mathrm{rpm}$ for $1 \mathrm{~min}$ to remove some non-exfoliated graphite. After that, the black suspension was centrifuged at $8000 \mathrm{rpm}$ for $10 \mathrm{~min}$ and then the water was removed. One $\mathrm{mL}$ of acetone was added to dissolve the black powder and then this mixture was transferred to a Petri dish and dried at $50{ }^{\circ} \mathrm{C}$ for $4 \mathrm{~h}$. The method allowed obtaining $800 \mathrm{mg}$ of biographene-1, final yield of $80 \%$ using TLL and $600 \mathrm{mg}$, $60 \%$ yield using CAL-B.

\subsubsection{Method 4: Double Sonication of Graphite Flakes in the Presence of Lipase}

The graphite flakes $(1 \mathrm{~g})$ were added to a solution of $20 \mathrm{~mL}$ of water to which $0.43 \mathrm{~mL}$ of commercial lipase was previously added in the case of TLL or $1 \mathrm{~mL}$ in the case of CAL-B, (enzymatic loading: 5 mgenzyme/gsupport). Then this mixture was sonicated using the aforementioned Method 2. After that, the mixture was transferred to $15 \mathrm{~mL}$ Falcon centrifuge tubes and centrifuged at $400 \mathrm{rpm}$ for $1 \mathrm{~min}$. The supernatant was carefully separated from the unfolded graphite solid. After that, the black suspension was centrifuged at $8000 \mathrm{rpm}$ for $10 \mathrm{~min}$ and then the water was removed. One $\mathrm{mL}$ of acetone was added to dissolve the black powder and then this mixture was transferred to a Petri dish and dried at $50{ }^{\circ} \mathrm{C}$ for $4 \mathrm{~h}$. The method allowed obtaining $500 \mathrm{mg}$ of biographene-2, final yield of $50 \%$. 


\subsection{Hydrolytic Activity Assay of $p N P P$}

This assay was performed by measuring the increase in the absorbance at $348 \mathrm{~nm}$ produced by the release of p-nitrophenol in the hydrolysis of $0.4 \mathrm{mM}$ pNPP in $25 \mathrm{mM}$ sodium phosphate buffer at $\mathrm{pH} 7$ and $25{ }^{\circ} \mathrm{C}$. To initialize the reaction, $20 \mu \mathrm{L}$ of lipase solution or suspension was added to $2.5 \mathrm{~mL}$ of substrate solution. One international unit of pNPP activity was defined as the amount of enzyme that is necessary to hydrolyze $1 \mu \mathrm{mol}$ of pNPP per minute (IU) under the conditions described previously.

\section{Results}

Four different methods have been performed in order to produce graphene from cheap graphite flakes.

First, two different methods based on a mechanical force through ultrasound to the flakes of graphite were tested, one with a simple mechanical sonication (Method 1) and another with double sonication (Method 2) of graphite flakes in distilled water. After that, two materials, Sgraphene-1 and Sgraphene-2 were obtained. These strategies gave moderate to low yields of graphene (black suspension) of $10 \%$ to $30 \%$, respectively.

If we focus on the observed differences between Sgraphene-1 (Simple Sonication) and Sgraphene-2 (Double sonication), for example in the SEM images, that material presented a larger flake size by using Method 1 (Figure 3A.1,B.1) than by double mechanical approach (Figure 3A.2,B.2), although in both cases clearly reduced respect to the starting commercial graphite flakes (Figure 3A,B.3). TEM analysis confirmed that Sgraphene-1 showed a higher density solid without forming sheets (Figure 3C.1) whereas Sgraphene-2, a much less dense sample was observed and in which the number of layers can be appreciated (Figure 3C.2). These results seem to indicate the need for applying ultrasound for a longer time on the sample, so that progress was made on Method 2.

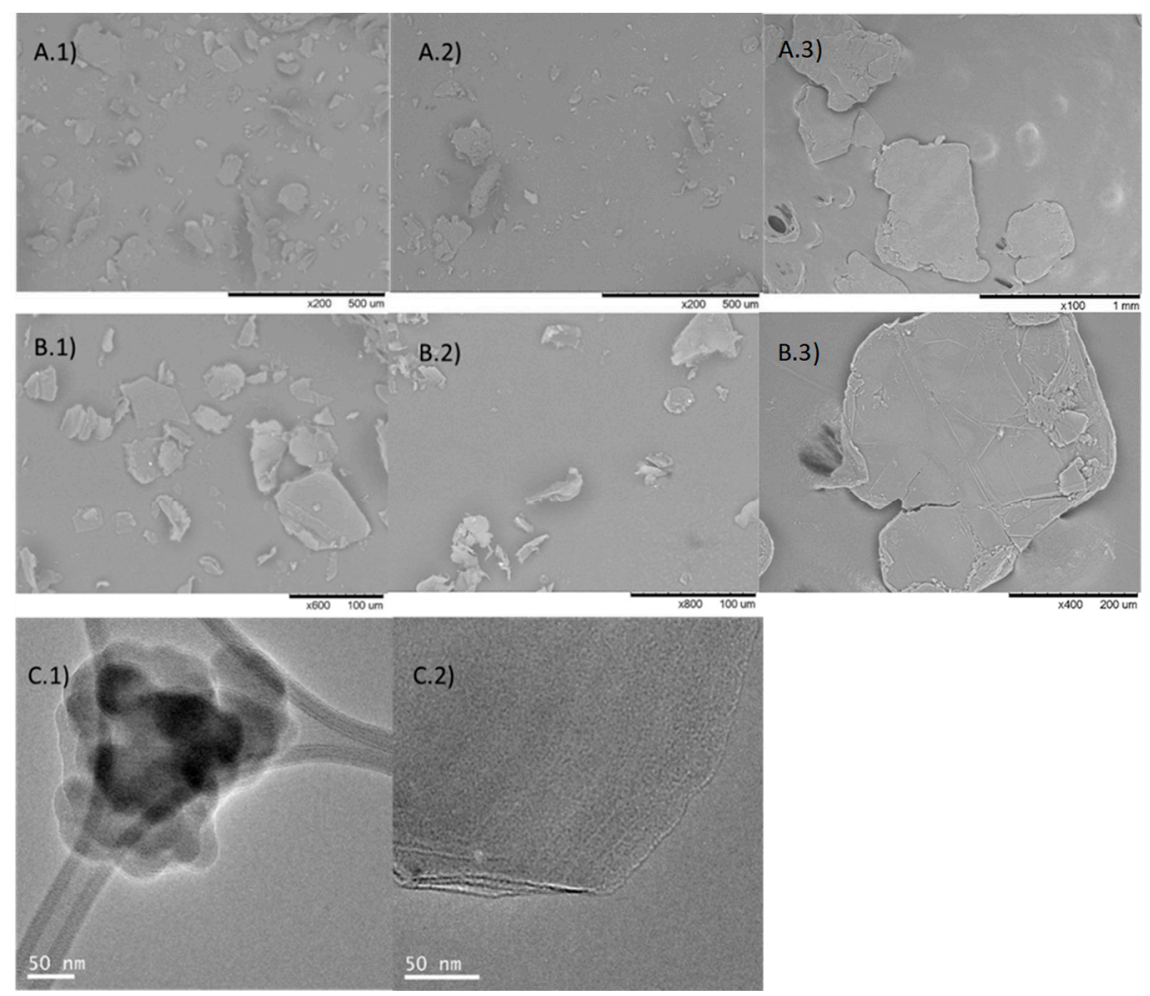

Figure 3. (A,B) SEM images. 1) Sgraphene-1, 2) Sgrapehene-2, 3) graphite flakes. (C) TEM images. 1) Sgraphene-1, 2) Sgrapehene-2. 
Considering the hydrophobic nature of graphene sheets [38] and the nature of the lipases, the next two different strategies were based on a bioexfoliation process using an enzyme combined with the sonication strategy in Method 2.

Method 3 was based on directly addition of the commercial liquid solution of lipase from C. antarctica B (CAL-B) or T. lanuginosus (TLL) on the Sgraphene-2 (Figure 4).
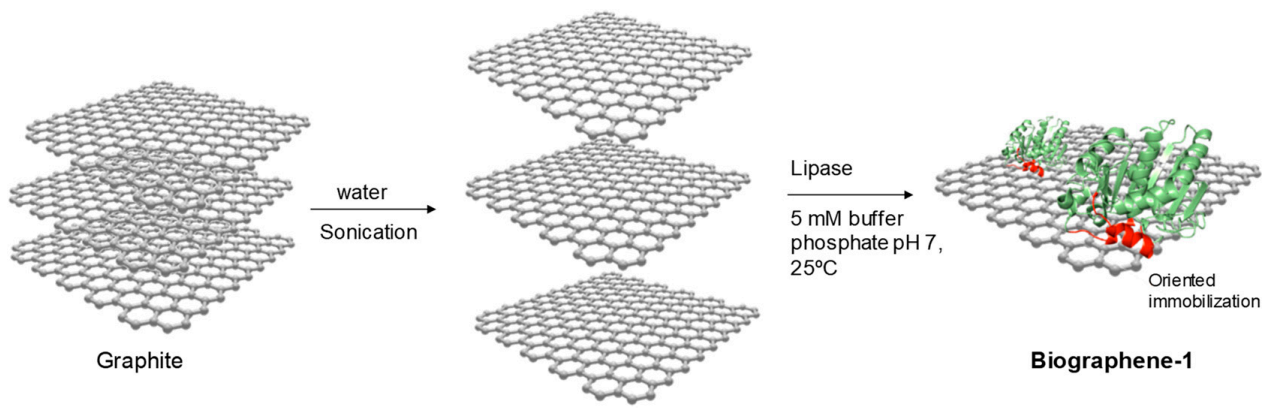

Biographene-1

Figure 4. Schematic representation of biographene-1 preparation by Method 3.

The lipase (loading of $5 \mathrm{mg}$ enzyme/g support) was fully adsorbed to the solid material at room temperature. The spacing obtained previously between the graphite sheets allows the lipase to be placed between them, giving rise to hydrophobic sheet-lipase interactions (interfacial adsorption) that permit separating said sheets obtaining graphene (Figure 4).

The 100\% immobilization was determined by measuring the enzymatic activity using the pNPP assay of the supernatant and was achieved after $30 \mathrm{~min}$ for TLL whereas with CAL-B $1 \mathrm{~h}$ of incubation was necessary. Moreover, after recovery of the final biographene-1, the yield was higher using TLL than CAL-B, $80 \%$ against $60 \%$. These phenomena could be explained considering the aminoacid composition and tridimensional structure of both lipases. Although both enzymes have similar molecular weight, TLL presents a much higher hydrophobic area than CAL-B (Figure 2), which has an influence on the immobilization rate of the open confirmation of the lipase on the graphene surface and also on the final interaction between enzyme and support. At first glance, the differences were evident, the aqueous suspension of graphene obtained using TLL was a homogeneous black solution while in CAL-B, although the suspension was black, a black solid slip towards the bottom was observed. These differences are also defined in SEM and TEM analysis (Figures 5 and 6).

A

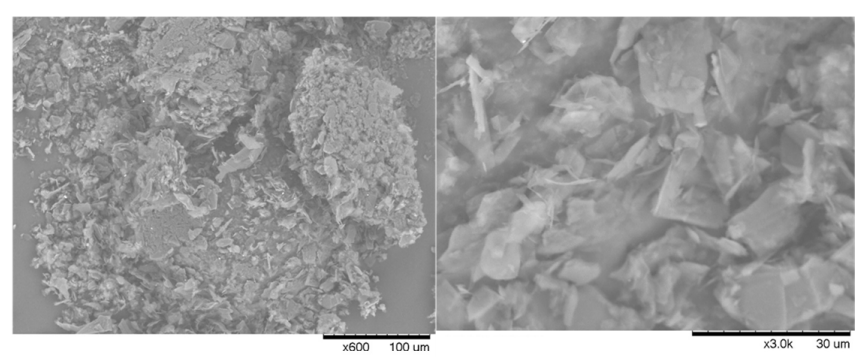

B
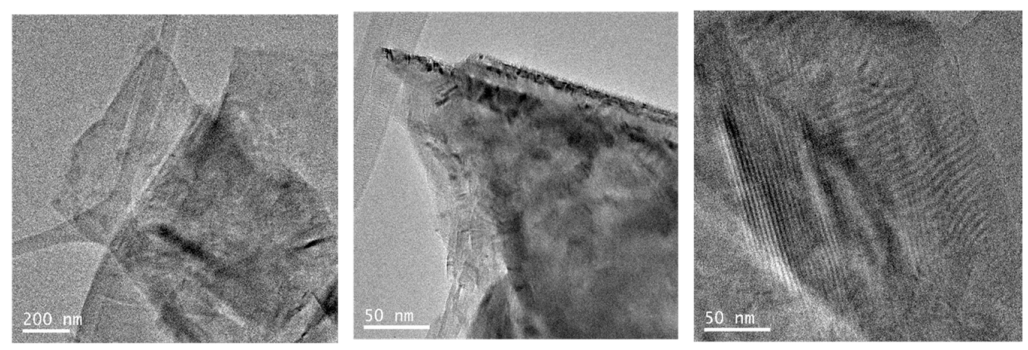

Figure 5. Characterization of biographene-1-CAL-B. (A) SEM Images. (B) TEM images. 
A
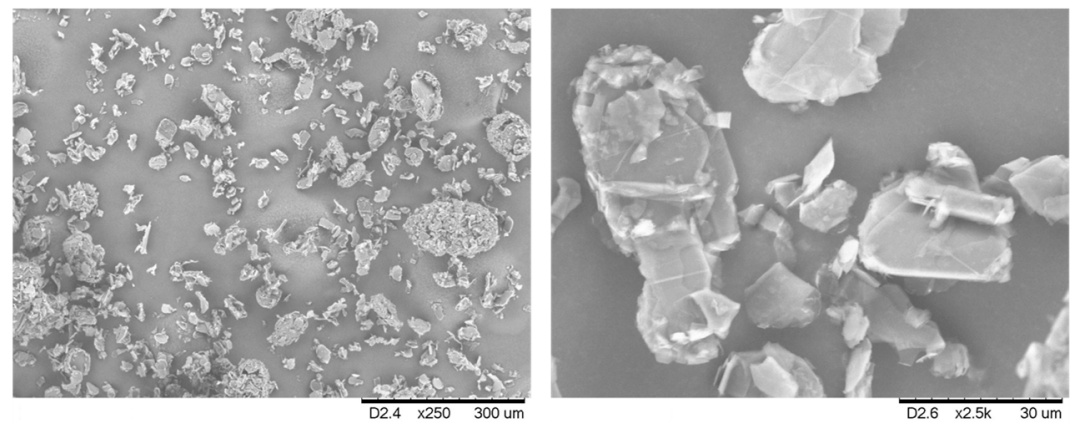

B
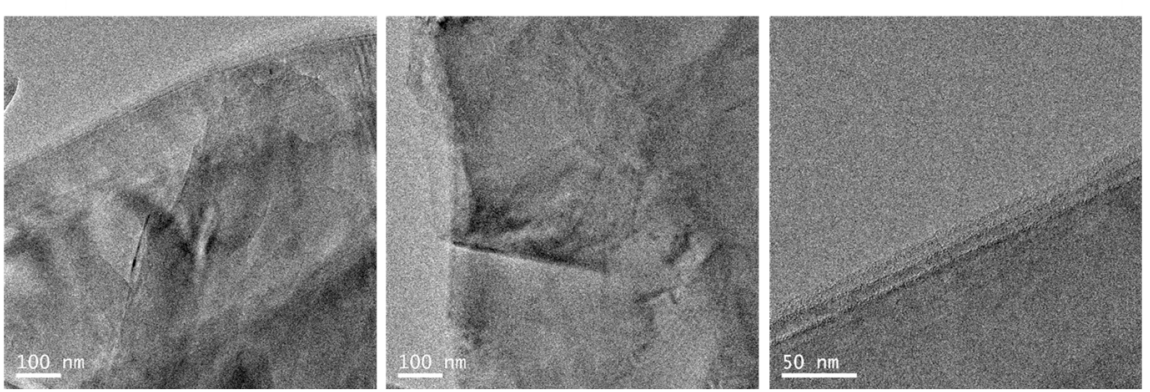

Figure 6. Characterization of biographene-1-TLL. (A) SEM Images. (B) TEM images.

By analysis of the biographene samples with scanning electron microscopy (SEM), the method using CALB seems to generate a material with a larger flake size when compared with the method using TLL (Figure 6). The TEM images of biographene-1 using CALB showed the presence of defects in the surface of the graphene sheets and also multiple layers superposition is seen in a disordered manner (Figure 5B). However, TEM images of biographene-1 using TLL showed a surface with fewer defects and the number of layers present in the graphene flake was below 10 , which can be observed in Figure $6 \mathrm{~B}(50 \mathrm{~nm})$.

Considering these promising results, a fourth method adding the enzyme directly from the beginning (sonication plus lipase immobilization in one-pot) was attempted (Figure 7).
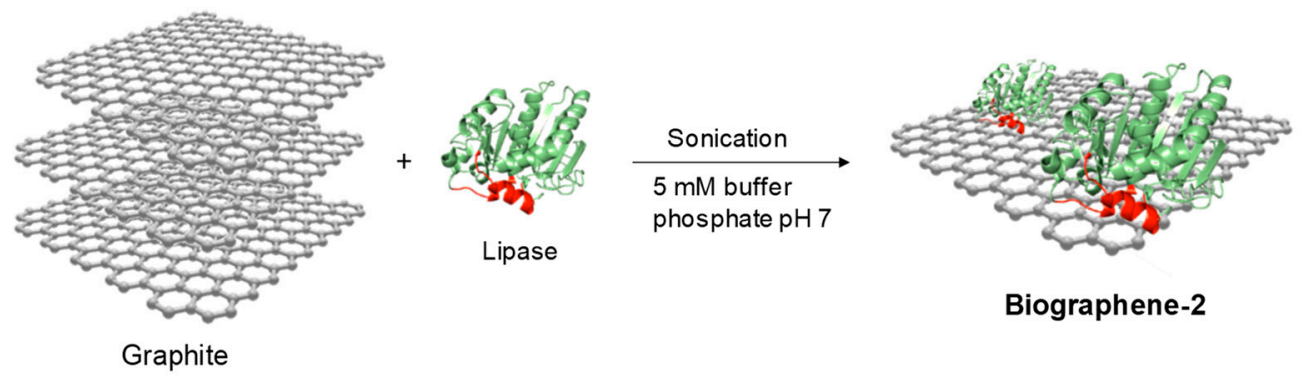

Biographene-2

Figure 7. Schematic representation of biographene-2 preparation by Method 4 .

The lipase must be introduced between the sheets of graphene while the ultrasound weakens this interaction between sheets separating them completely. The strategy was applied using shorter and longer sonication times. In this case, also both lipases were tested.

The best results were obtained using the longest strategy for mechanical sonication described in Method 2 but in the presence of the enzyme. However, in both cases, yields of black solid around $50 \%$ were obtained. TEM analysis demonstrated differences between using one lipase or the other (Figure 8). In the case of CAL-B (Figure 8A.1) the particle size was slightly larger than in TLL (Figure 8A.2). In addition, in the SEM images (Figure 8B.1,B.2) different morphologies were observed between them. 


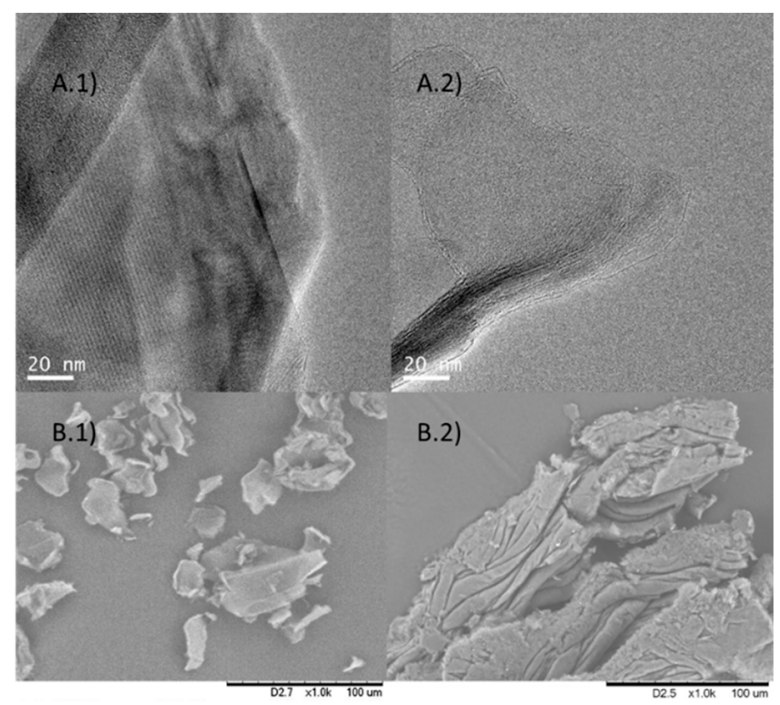

Figure 8. Characterization of biographene-2. (A) TEM images.1) CAL-B, 2) TLL, (B) SEM images. 1) CAL-B, 2) TLL.

However, when comparing this method with the aforementioned Method 3, the sizes of the obtained aggregates were much larger than in Method 3, together with a higher density of sheets.

In order to determine and confirm the formation of graphene-based materials in all the cases and to know the graphene quality and the number of layers, Raman experiments were performed (Figure 9). The results established that while clear differences between methods and enzymes were found, at least one of the methods (namely Method 3 using TLL as "delaminating enzyme") yielded interesting results (biographene-1-TLL). It should also be noted that the treatments applied to the different samples did not create more defects on the graphene layers, as evidenced by the comparable $\mathrm{D}$ band between the graphene samples and the parent graphite (see Supplementary Materials).

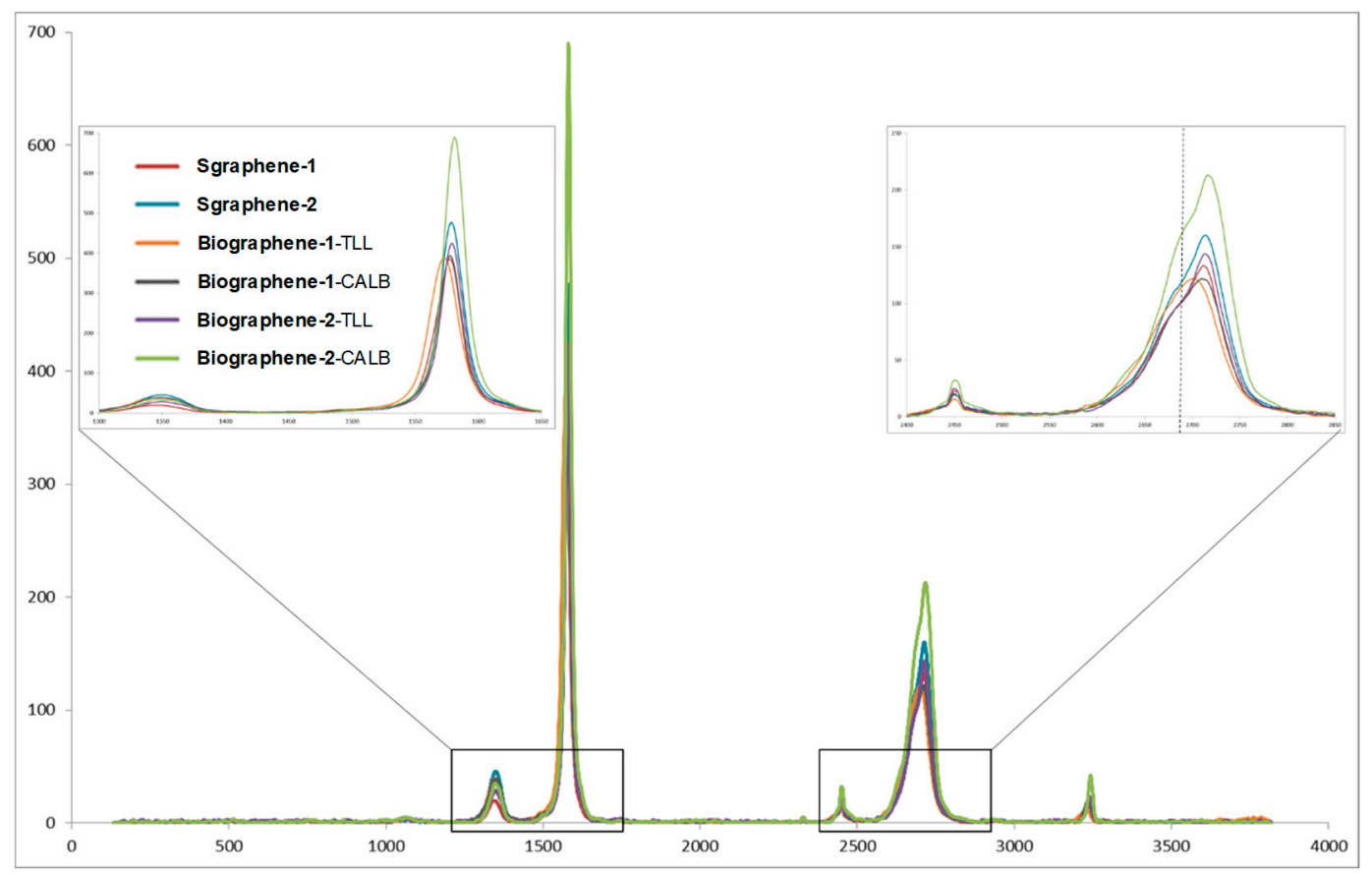

Figure 9. Raman spectra of the different biographene materials. 
The biographene-1-TLL showed the best results according to the Raman band range of $2600-2750 \mathrm{~cm}^{-1}$, which clearly showed that this case a multi-layer graphene (with a number of layers between 5 and 10) is obtained, because peak at $2710 \mathrm{~cm}^{-1}$ is mainly present [39]. In the other cases, mixtures of graphene with a number of layers over 10 was obtained. These results reinforce the idea that better results are found using lipase with higher hydrophobicity as TLL in comparison with CAL-B. While other studies [40] have studied the splitting of the band appearing at $2450 \mathrm{~cm}^{-1}$ (called the $\mathrm{G} *$ or $\mathrm{D}+\mathrm{D}^{\prime \prime}$ band) and a function of the number of graphene layers, the results have focused on samples with a number of layers $<6$ and thus a comparison with our results may not be applicable.

In order to corroborate the promising results hinted at by the Raman spectra, AFM images were collected (see Supplementary Materials) and analyzed for their 2D profiles in order to obtain more information on the number of layers forming the graphene flakes. The depth profiles indicated several sections in which flakes with sizes ranging from 0.2 to $1 \mu \mathrm{m}$ had profile heights of 1.7 to $2 \mathrm{~nm}$, indicative of graphene domains formed up by five and six layers, respectively, which corroborates the aforementioned Raman results.

\section{Conclusions}

We have developed for the first time a very simple, rapid, low-cost, and environmentally safe process to produce graphene sheets from very cheap graphite flakes in water and room temperature.

The novelty consists in the application of a biomolecule, a lipase, an enzyme with a very high selectivity to interact with hydrophobic surfaces, fixing the open conformation which permits the location of lipases in open conformation uniformly distributed on the graphene sheets surface, avoiding the interactions between sheets, generating an exquisite bioexfoliation of graphite. Two different enzymes with different methods were employed and the use of Themomyces lanuginosus lipase (with a very high hydrophobic area) gave the best results. It was possible to produce multi-layer graphene (MLG) at $80 \%$ yield, obtaining $800 \mathrm{mg}$ of graphene per gram of graphite flakes by a very simple way. Additionally, this produced better quality (i.e., less damaged) biographene than commercial GO or rGO tested.

This is very important from an industrial point of view, because economically the advantage is clear, $1 \mathrm{~g}$ of graphite flakes costs 3.36 Eurocents (product from SIGMA, $2.5 \mathrm{~kg}$ to $€ 84$ ), whereas $1 \mathrm{~g}$ of graphene oxide costs $€ 524$ (SIGMA), that means it is 15,000 times cheaper. Another advantage of this produced biographene is that it is already functionalized, because the enzyme presents a high number of carboxylic groups in the area exposed to the solvent. Therefore, this strategy could have a high potential in the application of graphene in different areas (biomedicine, biosensors, etc).

Supplementary Materials: The following are available online at http://www.mdpi.com/2079-4991/9/9/1344/s1, Figure S1: Raman spectra of the parent graphite used in this manuscript, Figure S2: Representative AFM image (left) and inverse image (right) obtained for sample biographene-1-TLL.

Author Contributions: N.L-G., A.B.-M. performed the experiments; J.M.P. designed and supervised the study and experiments, A.B.-M. and D.C.-A. developed the RAMAN and AFM experiments and J.M.P., N.L.-G., A.B.-M. and D.C.-A. wrote the manuscript.

Funding: This research was supported by GRO PROGRAM 2017 and SAMSUNG L.S. The authors thank the support by the Spanish National Research Council (CSIC). We also thank to the and MCIUN and FEDER by funding Projects RTI2018-095291-B-I00 and RTI2018-095291-B-I00.

Acknowledgments: We thank Ramiro Martínez from Novozymes.

Conflicts of Interest: The authors declare no conflicts of interest

\section{References}

1. Geim, A.K. Graphene: Status and prospects. Science 2009, 324, 1530-1534. [CrossRef] [PubMed]

2. Wang, Q.H.; Kalantar-Zadeh, K.; Kis, A.; Coleman, J.N.; Strano, M.S. Electronics and optoelectronics of two-dimensional transition metal dichalcogenides. Nat. Nanotechnol. 2012, 7, 699-712. [CrossRef] [PubMed] 
3. Bolisetty, S.; Peydayesh, M.; Mezzenga, R. Sustainable technologies for water purification from heavy metals: Review and analysis. Chem. Soc. Rev. 2019, 48, 463-487. [CrossRef] [PubMed]

4. Novoselov, K.S.; Fal'Ko, V.I.; Colombo, L.; Gellert, P.R.; Schwab, M.G.; Kim, K.A. A roadmap for graphene. Nature 2012, 490, 192-200. [CrossRef] [PubMed]

5. Schwierz, F. Graphene transistors. Nat. Nanotechnol. 2010, 5, 487-496.

6. Balandin, A.A. Thermal properties of graphene and nanostructured carbon materials. Nat.Mat. 2011, 10, 569-581. [CrossRef] [PubMed]

7. Goodenough, J.B.; Park, K.-S. The Li-ion rechargeable battery: A perspective. J.Am.Chem.Soc. 2013, 135, 1167-1176. [CrossRef]

8. Bonaccorso, F.; Colombo, L.; Yu, G.; Stoller, M.; Tozzini, V.; Ferrari, A.C.; Ruoff, R.S.; Pellegrini, V. Graphene, related two-dimensional crystals, and hybrid systems for energy conversion and storage. Science 2015, 347, 1246501. [CrossRef]

9. Yang, K.; Feng, L.; Shi, X.; Liu, Z. Nano-graphene in biomedicine: Theranostic applications. Chem. Soc. Rev. 2013, 42, 530-547. [CrossRef]

10. Mak, K.F.; Shan, J. Photonics and optoelectronics of 2D semiconductor transition metal dichalcogenides. Nat. Photonics 2016, 10, 216-226. [CrossRef]

11. Yao, S.; Zhu, Y. Nanomaterial-enabled stretchable conductors: Strategies, materials and devices. Adv. Mat. 2015, 27, 1480-1511. [CrossRef] [PubMed]

12. Manzeli, S.; Ovchinnikov, D.; Pasquier, D.; Yazyev, O.V.; Kis, A. 2D transition metal dichalcogenides. Nat. Rev. Mat. 2017, 2, 17033. [CrossRef]

13. Chen, D.; Zhang, H.; Liu, Y.; Li, J. Graphene and its derivatives for the development of solar cells, photoelectrochemical and photocatalytic applications. Energy Environ. Sci. 2013, 6, 1362-1387. [CrossRef]

14. Novoselov, K.S.; McCann, E.; Morozov, S.V.; Falko, V.I.; Katsnelson, M.I.; Zeitler, U.; Jiang, D.; Schedin, F.; Geim, A.K. Unconventional quantum Hall effect and Berry's phase of $2 \pi$ in bilayer graphene. Nat. Phys. 2006, 2, 177-180.

15. Zhou, X.; Liu, Z. A scalable, solution-phase processing route to graphene oxide and graphene ultralarge sheets. Chem. Commun. 2010, 46, 2611-2613. [CrossRef] [PubMed]

16. Georgakilas, V.; Otyepka, M.; Bourlinos, A.B.; Chandra, V.; Kim, N.; Kemp, K.C.; Hobza, P.; Zboril, R.; Kim, K.S. Functionalization of graphene: Covalent and non-covalent approaches, derivatives and applications. Chem. Rev. 2012, 112, 6156-6214.

17. Park, S.; Ruoff, R.S. Chemical methods for the production of graphenes. Nat. Nanotechnol. 2009, 4, $217-224$.

18. Tung, V.C.; Allen, M.J.; Yang, Y.; Kaner, R.B. High-throughput solution processing of large-scale graphene. Nat. Nanotechnol. 2009, 4, 25-29. [CrossRef]

19. Gravagnuolo, A.M.; Morales-Narváez, E.; Longobardi, S.; da Silva, E.T.; Giardina, P.; Merkoçi, A. In Situ Production of Biofunctionalized Few-Layer Defect-Free Microsheets of Graphene. Adv. Funct. Mater. 2015, 25, 2771-2779. [CrossRef]

20. Shin, H.J.; Kim, K.K.; Benayad, A.; Yoon, S.M.; Park, H.K.; Jung, I.S.; Jim, M.H.; Jeong, H.K.; Kim, J.M.; Choi, J.Y. Efficient Reduction of Graphite Oxide by Sodium Borohydride and Its Effect on Electrical Conductance. Adv. Funct. Mater. 2009, 19, 1987-1992. [CrossRef]

21. Wei, P.; Gan, T.; Wu, K. N-methyl-2-pyrrolidone exfoliated graphene as highly sensitive analytical platform for carbendazim. Sens. Actuators B Chem. 2018, 274, 551-559. [CrossRef]

22. León, V.; Rodriguez, A.M.; Prieto, P.; Prato, M.; Vázquez, E. Exfoliation of Graphite with Triazine Derivatives under Ball-Milling Conditions: Preparation of Few-Layer Graphene via Selective Noncovalent Interactions. ACS Nano 2014, 8, 563-571. [CrossRef]

23. Zhao, S.; Xie, S.; Zhao, Z.; Zhang, J.; Li, L.; Xin, Z. Efficiency Production of Graphene by Tannic Acid-Assisted Exfoliation of Graphite in Water. ACS Sust. Chem. Eng. 2018, 6, 7652-7661. [CrossRef]

24. Zhuo, H.; Zhang, X.; Wang, L.; Lu, Q.; Kaplan, D.L. Sonication Exfoliation of Defect-Free Graphene in Aqueous Silk Nanofiber Solutions. ACS Sust. Chem. Eng. 2018, 6, 12261-12267. [CrossRef]

25. Wang, Y.-Z.; Chen, T.; Liu, H.-H.; Wang, X.-C.; Zhang, X.-X. Direct Liquid Phase Exfoliation of Graphite to Produce Few-Layer Graphene by Microfluidization. J. Nanosci. Nanotechnol. 2019, 9, 2078-2086. [CrossRef] [PubMed]

26. Salunke, B.K.; Kim, B.S. Facile synthesis of graphene using a biological method. RSC Adv. 2016, 6, 17158. [CrossRef] 
27. Pattammattel., A.; Kumar, C.V. Kitchen Chemistry 101: Multigram Production of High Quality Biographene in a Blender with Edible Proteins. Adv. Funct. Mater. 2015, 25, 7088-7098. [CrossRef]

28. Laaksonen, P.; Kainlauri, M.; Laaksonen, T.; Shchepetov, A.; Jiang, H.; Ahopelto, J.; Linder, M.B. Interfacial engineering by proteins: Exfoliation and functionalization of graphene by hydrophobins. Angew. Chem. Int. Ed 2010, 49, 4946-4949. [CrossRef] [PubMed]

29. Babu, D.B.; Ramesha, K. Melamine assisted liquid exfoliation approach for the synthesis of nitrogen doped graphene-like carbon nano sheets from bio-waste bagasse material and its application towards high areal density Li-S batteries. Carbon 2019, 144, 582-590. [CrossRef]

30. Linder, M.B.; Szilvay, G.; Nakari-Setälä, T.; Penttilä, M. Hydrophobins: The protein-amphiphiles of filamentous fungi. FEMS Microbiol. Rev. 2005, 29, 877-896. [CrossRef] [PubMed]

31. Van Tilbeurgh, H.; Egloff, M.P.; Martinez, C.; Rugani, N.; Verger, R.; Cambillau, C. Interfacial activation of the lipase-procolipase complex by mixed micelles revealed by X-ray crystallography. Nature. 1993, 362, 814-820. [CrossRef]

32. Marciello, M.; Filice, M.; Palomo, J.M. Different strategies to enhance activities of lipase catalysts. Catal Sci. Technol. 2012, 2, 1531-1543. [CrossRef]

33. Palomo, J.M.; Munoz, G.; Fernandez-Lorente, G.; Mateo, C.; Fernandez-Lafuente, R.; Guisan, J.M. Interfacial adsorption of lipases on very hydrophobic support (octadecyl-Sepabeads): Immobilization, hyperactivation and stabilization of the open form of lipases. J. Mol. Catal. B: Enzym. 2002, 19-20, 279-286. [CrossRef]

34. Palomo, J.M.; Fuentes, M.; Fernández-Lorente, G.; Mateo, C.; Guisan, J.M.; Fernández-Lafuente, R. General trend of Lipase to auto-assemble giving bi-molecular aggregates greatly modifies the enzyme functionality. Biomacromolecules 2003, 4, 1-6. [CrossRef] [PubMed]

35. Fernández-Lorente, G.; Palomo, J.M.; Cabrera, Z.; Guisan, J.M.; Fernandez-Lafuente, R. Specificity enhancement towards hydrophobic substrates by immobilization of lipases by interfacial activation on hydrophobic supports. Enzyme Microb. Technol. 2007, 41, 565-569.

36. Hermanová, S.; Zarevúcká, M.; Bouša, D.; Mikulics, M.; Sofer, Z. Lipase enzymes on graphene oxide support for high-efficiency Biocatalysis. App. Mat. Today 2016, 5, 200-208.

37. Mathesh, M.; Luan, B.; Akanbi, T.O.; Weber, J.K.; Liu, J.; Barrow, C.J.; Zhou, R.; Yang, W. Opening Lids: Modulation of Lipase Immobilization by Graphene Oxides. ACS Catal. 2016, 6, 4760-4768. [CrossRef]

38. Shih, C.-J.; Strano, M.S.; Blankschtein, D. Wetting translucency of graphene. Nature Mat. 2013, 12, 866-869. [CrossRef] [PubMed]

39. Graf, D.; Molitor, F.; Ensslin, K.; Stampfer, C.; Jungen, A.; Hierold, C.; Wirtz, L. Spatially resolved Raman spectroscopy of single- and few-layer graphene. Nano Lett. 2007, 7, 238-242. [CrossRef]

40. May, P.; Lazzeri, M.; Venezuela, P.; Herziger, F.; Callsen, G.; Reparaz, J.S.; Hoffmann, A.; Mauri, F.; Maultszch, J. Signature of the two-dimensional phonon dispersion in graphene probed by double-resonantRaman scattering. Phys. Rev. B 2013, 87, 075402/1-6. [CrossRef]

(C) 2019 by the authors. Licensee MDPI, Basel, Switzerland. This article is an open access article distributed under the terms and conditions of the Creative Commons Attribution (CC BY) license (http://creativecommons.org/licenses/by/4.0/). 